\title{
ATUAÇÃO DO PSICÓLOGO NAS \\ INSTITUIÇÕES DE LONGA PERMANÊNCIA PARA IDOSOS
}

\author{
Paula Raquelyne Magalhães ${ }^{1}$ \\ Karla Priscilla Lemgruber ${ }^{2}$
}

\section{RESUMO}

INTRODUÇÃO: O aumento da expectativa de vida do ser humano é uma das várias mudanças ocorridas para a sociedade. O homem passou a viver mais; o que trouxe consigo um vertiginoso aumento no número de idosos. A responsabilidade pelo idoso é claramente atribuída à família, porém, inúmeras vezes, não o fazem devido às demais obrigações, assim esses idosos são resguardados e protegidos pela constituição, devem gozar, por lei, de uma velhice assistida, na inexistência da família, no abandono ou por carência de recursos. $O$ Estado por sua vez acompanha estes para instituições de longa permanência para Idosos (ILPIs). Afim disso as ILPIs deve se adaptar-se aos seus internos com oportunidades e suporte adequado às suas necessidades, bem como condições psíquicas. Pode-se observar que a literatura já existente é escassa e deixa vaga a real compreensão da atuação do psicólogo nesse campo. OBJETIVO: O presente estudo teve como objetivo investigar as situações e formas de atuação do psicólogo nas instituições de longa permanência para idosos bem como a eficácia de intervenções terapêuticas no processo de socialização dos mesmos. MÉTODO: A metodologia foi realizada através de revisão bibliográfica qualitativa do tipo descritivo, usando artigos científicos, livros, monografias, dissertações, teses adquiridas em bibliotecas de ensino superior, análise documental, dados de internet como SCIELO e Google acadêmico. As obras utilizadas foram de 2002 a 2012. Sendo encontrados no campo da psicologia nove artigos onde seis tinham o objetivo de investigar a socialização dos idosos institucionalizados. A Metodologia usada pelos seis periódicos foi estudo transversal,

\footnotetext{
1 Acadêmica do curso de psicologia da Faculdade Patos de Minas - FPM. E-mail de contato: paullaraquelyne@hotmail.com

2 Docente do departamento de Psicologia da Faculdade Patos de Minas - FPM.
} 

descritivo e observacional. RESULTADOS: O estudo propiciou informações claras acerca da atuação do Psicólogo nas ILPIs. É possível afirmar que é necessário o desenvolvimento de mais estudos referentes ao tema, vez que existem limitações para conclusões precisas. $\mathrm{Na}$ maioria das vezes a amostra é pequena, pois o número de profissionais na área é pequeno, ou porque os próprios idosos constituintes na amostra não são capazes de responder aos questionários com exatidão devido às suas limitações. O que faz com que os resultados, muitas das vezes, sejam subjetivos. DISCUSSÃO: Na rotina das ILPIs, a intervenção do psicólogo pode se dar por diversos meios, mais especificamente em três esferas. A primeira esfera são os próprios idosos, a segunda esfera a família dos idosos e a terceira esfera, os funcionários da instituição. A integração dessas esferas, cada uma com o seu limite de atuação, sem dúvida, estaria contribuindo para a melhoria da qualidade de vida dos idosos. CONSIDERAÇÕES FINAIS: Por meio desse estudo, pode-se concluir que o Brasil, em uma visão geral, ainda engatinha quando o assunto é a atuação dos psicólogos nas ILPIs e o envelhecimento bem-sucedido. Outros estudos devem ser realizados a fim de encontrar mais achados sobre o tema proporcionando maior esclarecimento sobre o processo de envelhecimento, melhorando a compreensão e capacitação dos profissionais que trabalham nessa área, podendo então, oferecer melhores condições de atendimento a esta população.

Palavras-chave: ILPIs; Socialização; Papel do Psicólogo; Atendimento. 